\title{
Pediyatrik Dermatopatolojide Biyopsinin Rolü
}

\section{The Role of Biopsy in Pediatric Dermatopathology}

\author{
Fatma Șule Afșar, Safiye Aktaș*, Gülden Diniz**, Ragıp Ortaç** \\ Atatürk Araștırma ve Eğitim Hastanesi, Deri ve Zührevi Hastalıklar Kliniği, İzmir, Türkiye \\ *Dokuz Eylül Üniversitesi, Onkoloji Enstitüsü, İzmir, Türkiye \\ **Dr. Behçet Uz Çocuk Hastanesi, Patoloji Bölümü, İzmir, Türkiye
}

\section{Özet}

Amaç: Pediyatrik dermatoloji erișkinler ile karșılaștırıldığında deri hastalıklarının farklı sıklıklarla görülmesi ile karakterizedir. Deri biyopsileri ayırıcı tanıda gereklidir ve klinikopatolojik korelasyon çok önemlidir. Bu çalıșmanın amacı ayıııcı tanı için deri biyopsisi alınan pediatrik dermatoloji olgularını retrospektif olarak değerlendirmek ve biyopsinin deri hastalıklarında tanıya katkısını irdelemekti.

Gereç ve Yöntem: Üç yıllık period boyunca pediyatrik dermatoloji kliniğinde biyopsi alınan olgular ön tanılar, biyopsi tanıları ve biyopsi bașarısı açısından retrospektif olarak değerlendirildi.

Bulgular: Toplam 12420 adet hastanın 213'üne $(\% 1,7)$ biyopsi uygulanmıștı. Henoch-Schönlein purpurası, psoriasis, pityriasis likenoides, pitriyasis rosea, liken planus, pitriyasis rubra pilaris, eritema multiforme, atopik dermatit, granuloma anulare, pigmente purpurik dermatoz dermatopatolojik olarak en sık tanı konan deri hastalıkları idi. Toplam $120(\% 56,3)$ olguda biyopsi tanısı ön tanılar içinde yer almakta olup, biyopsi uyumu mevcuttu. Yirmi beș $(\% 11,7)$ olguda biyopsi ayırıcı tanıya katkı sağlamamıștı. On $(\% 4,6)$ olguda ön tanılardan hiçbiri ile uymayan farklı kesin tanı rapor edildiği saptandı.

Sonuç: Pediyatrik dermatolojide deri biyopsisi ayırıcı tanıya çok yardımcıdır. Hastaya kolaylık sağlayan bir biyopsi alma ișlemi, biyopsi indikasyonunun etkin konulması, iyi bir dermatopatolojik korelasyon ve deneyimli bir pediyatrik dermatopatoloji ekibi ile deri biyopsilerinin bașarısı artmaktadır. (Türkderm 2011; 45: 137-9)

Anahtar Kelimeler: Pediyatrik, dermatopatoloji, biyopsi, klinikopatolojik korelasyon

\section{Summary}

Background and Design: Pediatric dermatology is characterized by skin disorders which have frequencies different from those in adults. Skin biopsies are necessary for differential diagnosis and clinicopathologic correlation is very important. The aim of this study was to evaluate retrospectively the pediatric dermatology cases in whom biopsy was performed for differential diagnosis and to investigate the contribution of biopsy to diagnosis of skin disorders.

Material and Methods: The cases from whom biopsy was taken in the pediatric dermatology clinic during a three-year period were evaluated retrospectively for pre-diagnoses, biopsy diagnoses, and success of biopsies.

Results: Two hundred thirteen (1.7\%) skin biopsies had been taken from a total of 12420 patients. Henoch-Schönlein purpura, psoriasis, pityriasis lichenoides, pityriasis rosea, lichen planus, pityriasis rubra pilaris, erythema multiforme, atopic dermatitis, granuloma annulare, and pigmented purpuric dermatosis were the most frequent skin disorders diagnosed dermatopathologically. In a total of $120(56.3 \%)$ cases, the biopsy diagnosis was within the pre-diagnosis and a biopsy consistency was present. In 25 $(11.7 \%)$ cases, biopsy had no contribution to the differential diagnosis. An absolutely different diagnosis which was incompatible with the pre-diagnosis had been reported in $10(4.6 \%)$ cases.

Conclusion: In pediatric dermatology, skin biopsy is very helpful for the differential diagnosis. An easy biopsy procedure for the patient, an effective designation of biopsy indication, a good dermatopathologic correlation and an experienced team of pediatric dermatopathology increase the success of skin biopsies. (Turkderm 2011;45: 137-9)

Key Words: Paediatric, dermatopathology, biopsy, clinicopathologic correlation

Yazıșma Adresi/Address for Correspondence: Dr. Fatma Sule Afșar, Atatürk Arastırma ve Eğitim Hastanesi, Dermatoloji Bölümü, Izmir, Türkiye Tel.: +90 23224343 43/2963 E-posta: suleafsar@hotmail.com Geliş Tarihi/Received: 02.11.2010 Kabul Tarihi/Accepted: 02.1 1.2010

Türkderm-Deri Hastalıkları ve Frengi Arșivi Dergisi, Galenos Yayınevi tarafından basılmıștır.

Turkderm-Archives of the Turkish Dermatology and Venerology, published by Galenos Publishing. 


\section{Giriş}

Erişkin çağında görülen her dermatolojik hastalık pediyatrik populasyonda da görülür. Ancak görülme sıklıkları değişiktir.1.3 Benin pigmentli lezyonlar, plastik cerrahi düzeltme materyalleri ve debritmanlar hariç tutulursa pediyatride sık görülen ve biyopsi gerektiren dermatolojik hastalıklar inflamatuvar lezyonlardır. Bunlara vaskülitler, psoriasis ve benzeri dermatozlar, liken planus ve likenoid erüpsiyonlar, pitriyasis likenoides ve vezikülobüllöz hastalıklar dahildir. ${ }^{5-15}$ Deriyi de tutan birçok konjenital hastalık klinik olarak tanınır ve biyopsi gerektirmez. Dermatopatolojide biyopsi ile tanıda algoritmik yaklaşım uygulanır. 16,17 Tanıda klinikopatolojik yaklaşım birçok patoloji alanından çok daha önemlidir. Bu çalışmanın amacı ayırıcı tanı için deri biyopsisi gerektiren pediyatrik dermatoloji olgularını retrospektif olarak değerlendirmek ve biyopsinin tanıya katkısını irdelemekti.

\section{Gereç ve Yöntem}

2006-2009 yılları süresince pediyatrik dermatoloji kliniğinde değerlendirilmiş 12420 olgudan ayırıcı tanı amaçlı biyopsi uygulanmış 213

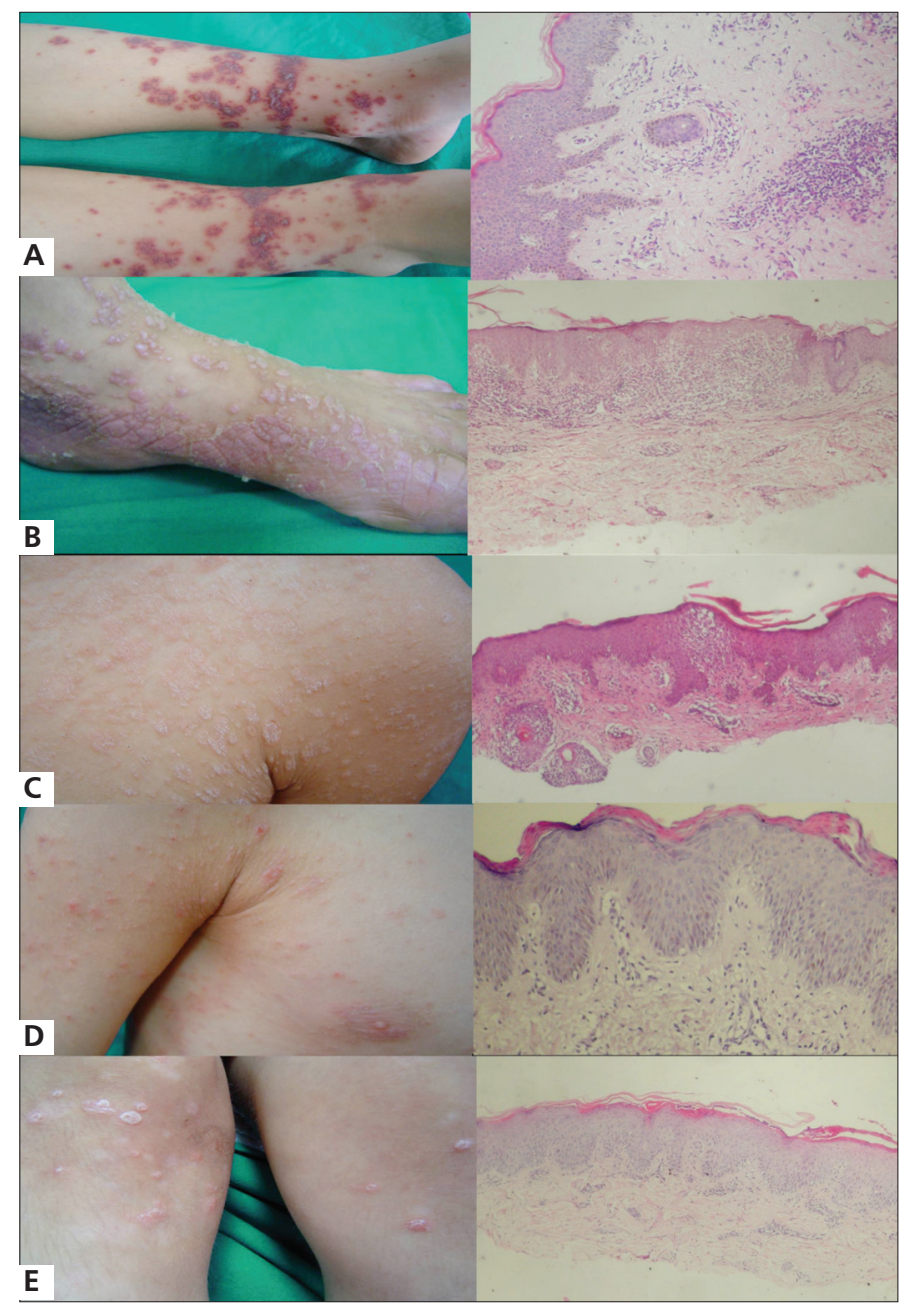

Şekil 1. Biyopsi ile en sık tanı konan olgulara ait klinik ve histopatolojik görünümler. 1A: Henoch-Schönlein purpurası (Hematoksilen-eozin x100). 1B: Liken planus (Hematoksileneozin x 40). 1C: Pitriyasis rosea (Hematoksilen-eozin x 40). 1D: Pitriyasis likenoides (Hematoksilen-eozin x100). 1E: Psoriasis (Hematoksilen-eozin x 40) adet olgu ön tanı, tanı, biyopsinin tanıya katkısı, biyopsinin yeterliliği, biyopsi sonrası kesinleşen tanıların ön tanılardan kaçıncısı olduğu yönünden değerlendirilmiştir.

\section{Bulgular}

Üç yıllık süreçte pediyatrik dermatoloji kliniğinde görülen 12420 adet hastanın (yaş aralığı 0-16 yaş) 213'üne $(\% 1,7)$ biyopsi uygulanmıştı. Biyopsi ile en sık tanı konan 10 deri hastalığı sıklık sırasına göre Tablo-1'de görülmektedir. Biyopsi öncesi 26 olguda 1, 56 olguda 2, 77 olguda 3, 34 olguda 4, 17 olguda 5, 3 olguda ise 6 ön tanı yer almıştı. Birinci ön tanı ile biyopsi uyumu $75(\% 35,2)$ olguda vardı. İkinci tanı ile uyum $23(\% 10,7)$ olguda, üçüncü tanı ve sonrası ile uyum $22(\% 10,3)$ olguda vardı. Yüz yirmi $(\% 56,3)$ olguda biyopsi tanısı ön tanılar içinde yer almakta olup, biyopsi uyumu mevcuttu. On bir $(\% 5,1)$ olguda biyopsi kısıtlı yeterli olup, $25(\% 11,7)$ olguda biyopsi tanıya katkı sağlamamıştı. Kırk yedi $(\% 22,0)$ olguda spesifik tanı verilemeyip, histopatolojik tanımlama yapılmış olup, bunların 12 'sinin $(\% 5,6)$ yorum ile ön tanılardan birisinin lehine olduğu bildirilmişti. Diğerlerinde biyopsi için kesin tanı bildirilmemiş ya da yorumlanamamıştı. On $(\% 4,6)$ olguda ön tanılardan hiçbiri ile uymayan farklı kesin tanı verilmişti. Bir olguda ön tanıda hiç düşünülmemiş olan Langerhans hücreli histiyositoz, 1 olguda da akut myeloid lösemi infiltrasyonu tanısı biyopsi ile konmuştu. Sonuç olarak toplam $130(\% 61,0)$ olguda biyopsiyle kesin tanı verilmişti. Biyopsi ile en sık olarak tanı konan olgulardan 5'inin klinik ve histopatolojik görünümleri Şekil-1'de görülmektedir.

\section{Tartışma}

Kutanöz hastalıkların tanısında dermatopatoloji bir asıra yakın zamandır çok önemli bir rol oynamaktadır. Elektron mikroskopi, immunfloresan mikroskopi ve immunhistokimya tanı kapasitesinin artmasına ve hastalıkların patogenezinin daha iyi anlaşılmasına neden olmuştur. Bu teknik ve bilimsel ilerlemelere rağmen biyopsi örneklerinin ve bunlara eşlik eden klinik bilginin yetersiz olabilmesi dermatopatolog için tanı koymada kısıtlayıcı olmaktadır. ${ }^{18}$ Klinik informasyonun olmaması inflamatuvar deri hastalıklarının biyopsilerinin yorumlanmasındaki en büyük kısıtlamadır. Belirli klinik ipuçları göze çarpmayan histolojik bulguların daha iyi incelenmesini sağlayabilir. ${ }^{19}$

Inflamatuvar veya diğer deri hastalıklarının histolojik tanısı için klinikopatolojik korelasyona ihtiyaç vardır ve hastalık ilerledikçe deri lezyonları değişik evrelerden geçerler ve birçok inflamatuvar süreçte hastalığın evresi histolojik özelliklerin tanısal olup olmadığını belirleyebi-

\section{Tablo 1. Pediatrik dermatolojide biyopsi ile en sık tanı konan} 10 deri hastalığı

\begin{tabular}{|l|c|}
\hline Tanı & (n) \\
\hline Henoch-Schönlein purpurası & 23 \\
\hline Psoriasis & 16 \\
\hline Pitriyasis likenoides & 14 \\
\hline Pitriyasis rosea & 11 \\
\hline Liken planus & 9 \\
\hline Pityriasis rubra pilaris & 8 \\
\hline Eritema multiforme & 7 \\
\hline Atopik dermatit & 6 \\
\hline Granuloma anulare & 3 \\
\hline Pigmente purpurik dermatoz & 3 \\
\hline
\end{tabular}


lir. ${ }^{16,19}$ Patolojik muayene çoğu kez tanının tamamlayıcı veya doğrulayıcı bir parçasıdır. Kesin dermatopatolojik tanı için önemli olan diğer faktörler optimum zamanlama, en iyi lokalizasyonu seçme ve deri biyopsisi için tercih edilen tekniklerdir. En karakteristik mikroskobik resim iyi gelişmiş bir lezyondan elde edilebilir. Mikroskobik bulgular ve klinik görünüm arasında uyuşmazlık olduğunda tekrar biyopsi alınmalıdır. Hastalık sürecinde biyopsi tekrarları genellikle gereklidir. Eğer daha önce alınmış bir biyopsi örneği mevcutsa tekrar incelenmeli ve yeni materyal ile birlikte göz önünde bulundurulmalıdır. ${ }^{16}$

Klinikopatolojik korelasyonun bir parçası olarak histopatolojik bulgular klinik görünüm, laboratuvar bulguları, hikaye ve hastalığın klinik seyri ile birlikte değerlendirilmelidir. ${ }^{16}$ Bu seride klinikopatolojik korelasyon iyi olduğu için biyopsi ile kesin tanı yazma oranı $(\% 61,0)$ yüksekti ve olguların $\% 56,3$ 'ünde biyopsi tanısı ön tanılar içinde yer almakta olup biyopsi uyumu mevcuttu. Pediyatrik dermatolojide deneyimli dermatoloji ve patoloji ekibi ile biyopsinin tanıya katkı oranı artmaktadır. Günümüzde biyopsi uygulanan olgulara dijital fotoğraflama yapılabilmektedir ve gerek duyulduğunda patoloji uzmanı bu fotoğraflara ulaşabilmektedir. ${ }^{3}$ Inflamatuvar dermatozların sorgulandığı 100 ardışık deri biyopsisini içeren bir çalışmada klinik bilgi verilmeden doğru tanı konma oranı \%53 iken, klinik bilgi verildikten sonra kesin tanı konma oranı \%78 olarak bulunmuştur. ${ }^{20}$ Dermatologlar ve dermatolog olmayanların aldıkları biyopsi sonuçlarını karşılaştıran bir çalışmada inflamatuvar deri hastalıklarına dermatologlar tarafından doğru tanı konma oranı \%71 iken bu oran dermatolog olmayanlarda \%34 olarak bulunmuş ve yeterli klinik bilgi olmadığında histolojik tanının kısıtlı olacağı vurgulanmıştır. ${ }^{21}$

Henoch-Schönlein purpurasında (HSP) deri biyopsisi böbrek biyopsisine göre çok daha kolay olup deri biyopsisi ile tanıya ulaşma oranı yüksektir. ${ }^{5}$ Tüm HSP ön tanılı deri biyopsileri laboratuvara acil tampon solüsyonunda ulaştırılıp immunfloresan ile birlikte çalışılmıştı. Pediatrik populasyonda tanısı daha zor olabilen psoriasis olgularına biyopsi katkısı tanıda yüksektir. ${ }^{722}$ Büllöz lezyonların sıklığı az olmakla birlikte ayırıcı tanıda biyopsi immunfloresan inceleme ile birlikte yardımcıdır. ${ }^{23}$ Deri biyopsileri lokal anestezi uygulandıktan sonra insizyonel yöntemle ve ek randevu gerekmeden dermatoloji uzmanı tarafından alınmaktadır. Biyopsinin bu yöntemle alınma kolaylığı avantaj sağlamaktadır. Sonuç olarak pediyatrik dermatolojide de deri biyopsisi ayırıcı tanıda çok yardımcıdır. Hastaya kolaylık sağlayan bir biyopsi alma işlemi, biyopsi indikasyonunun etkin konulması, iyi bir dermatopatolojik korelasyon ve deneyimli bir pediyatrik dermatopatoloji ekibi ile biyopsi başarısı artmaktadır.

\section{Kaynaklar}

1. Tamer $E$, Ilhan $M N$, Polat $M$, Lenk $N$, Alli $N$ : Prevalence of skin diseases among pediatric patients in Turkey. J Dermatol 2008;35:413-8.
2. Sardana K, Mahajan S, Sarkar R, Mendiratta V, Bhushan P, Koranne RV, et al: The spectrum of skin disease among Indian children. Pediatr Dermatol 2009;26:6-13.

3. Kutzner $H$, Kempf W, Schärer L, Requena L: Optimizing dermatopathologic diagnosis with digital photography and internet. The significance of clinicopathologic correlation. Hautarz 2007;58:760-8.

4. Sidbury R: What's new in pediatric dermatology: update for the pediatrician. Curr Opin Pediatr 2004;16:410-4.

5. Davin JC, Weening JJ: Diagnosis of Henoch-Schönlein purpura: renal or skin biopsy? Pediatr Nephrol 2003;18:1201-3.

6. González LM, Janniger CK, Schwartz RA: Pediatric Henoch-Schönlein purpura. Int J Dermatol 2009;48:1157-65.

7. Pirgon $\mathrm{O}$, Atabek ME, Sert A: Psoriasis following growth hormone therapy in a child. Ann Pharmacother 2007;41:157-60.

8. Farber EM, Nall L: Childhood psoriasis. Cutis 1999;64:309-14.

9. Herbst RA, Hoch O, Kapp A, Weiss J: Guttate psoriasis triggered by perianal streptococcal dermatitis in a four-year-old boy. J Am Acad Dermatol 2000;42:885-7.

10. Cohen DM, Ben-Amitai D, Feinmesser M, Zvulunov A: Childhood lichen planus pemphigoides: a case report and review of the literature. Pediatr Dermatol 2009;26:569-74.

11. Handa S, Sahoo B. Childhood lichen planus: a study of 87 cases. Int J Dermatol 2002;41:423-7.

12. Woo V, Bonks J, Borukhova L, Zegarelli D: Oral lichenoid drug eruption: a report of a pediatric case and review of the literature. Pediatr Dermatol 2009;26:458-64.

13. Rogers M: Pityriasis lichenoides and lymphomatoid papulosis. Semin Dermatol 1992;11:73-9.

14. Longley J, Demar L, Feinstein RP, Miller RL, Silvers DN: Clinical and histologic features of pityriasis lichenoides et varioliformis acuta in children. Arch Dermatol 1987;123:1335-9.

15. Kerkar N, Cohen S, Dugan C, Morotti RA, Phelps RG, Herold B, et al: Bullous pemphigoid after liver transplantation for liver failure. Liver Transpl 2006;12:1705-10.

16. Sina B, Kao GF, Deng AC, Gaspari AA: Skin biopsy for inflammatory and common neoplastic skin diseases: optimum time, best location and preferred techniques. A critical review. J Cutan Pathol 2009;36:505-10.

17. Gilliam AE: Skin signs of systemic disease in childhood. Adv Dermatol 2006;22:1-30.

18. Salem OS, Maize JC: Clinicopathologic correlation in diagnosis of diseases of the skin. Am J Dermatopathol 1986;8:53-6.

19. Mehregan DR, Dooley VN: How to get the most out of your skin biopsies. Int J Dermatol 2007:46:727-33.

20. Rajaratnam R, Smith AG, Biswas A, Stephens M: The value of skin biopsy in inflammmatory dermatoses. Am J Dermatopathol 2009;31:350-3.

21. Sellheyer K, Bergfeld WF: A retrospective biopsy study of the clinical diagnostic accuracy of common skin diseases by different specialties compared with dermatology. J Am Acad Dermatol 2005;52:823-30.

22. Nagle T: Topics in pediatric dermatology. Vet Clin North Am Small Anim Pract. 2006;36:557-72.

23. Essary LR, Hoang MP, Carder KR: Practical review and recent developments in pediatric dermatopathology. Adv Dermatol 2005;21:193-215. 